\title{
Meta-Analyze of the Scientific Papers on the Effects of the Preparation Period on the Situational Motor Skills of the Cadet Football Players
}

\author{
Ivan Vasiljevic \\ University of Montenegro, Faculty for Sport and Physical Education, Niksic, Montenegro
}

\begin{abstract}
A B S T R A C T
The main goal of the research was to make one meta-analyze of original scientific papers, mostly published in the Sport Mont Journal, who dealt with the identification of the level of quantitative changes in situational motor skills at cadet football players under the influence of the programmed training process in the preparation period. Three tests were used for estimation of each situational motor ability. In the field of comparative statistics, for determining the differences in variables used to estimate situational motor abilities at the beginning (starting state) and at the end (final state) of the training program during the preparation period, a discriminating parametric procedure t-test was used for large dependent samples. Based on the numerical values of t-test, in all the aforementioned published papers, it was the concluded that statistically significant positive quantitative changes occurred in situational motor skills during the preparation period of cadet football players. Such a training program during the preparation period proved to be very effective in raising the level of situational motor skills in cadet football players. This meta-analyze shows that the obtained results can be focused on innovative plans and programs in the preparation period as well as on adapting the same to the needs of the appropriate population.
\end{abstract}

Key words: Meta-Analysis, Sport Mont, Situational Motor Skills

\section{Uvod}

Danas je fudbal sigurno sport broj jedan u svijetu po gledanosti i popularnosti (Corluka \& Vasiljevic, 2018; Gardasevic, Bjelica, Popovic, Vasiljevic, \& Milosevic 2018 Bjelica, i Popović, 2012). Fudbal je sport koga odlikuju mnogobrojne i raznovrsne složene dinamičke kineziološke aktivnosti koje se odlikuju velikim brojem cikličnih i acikličnih kretanja (Gardašević, 2010; Sermaxhaj, Popovic, Bjelica, Gardasevic, \& Arifi, 2017). Evidentno je da sva četiri momenta igre, i posjed lopte, i posjed lopte protivnika, i transformacija po osvojenoj lopti i transformacija po izgubljenoj lopti zavise od mogućnosti igrača da izvedu određeno kretanje različitog intenziteta, u različitim pravcima i različitim dionicama igrališta (Gardašević, Georgiev \& Bjelica, 2012). Igrači za takve akcije moraju imati veoma razvijene motoričke sposobnosti (Vasiljević, Gardašević, \& Bojanić, 2013; Bjelica, Popović, \& Gardašević, 2016a; Vasiljevic, 2017). Ovdje je urađena meta analiza koja daje pregled objavljenih originalnih naučnih radova u časopisu Sport Mont. Analizirani su radovi objavljeni od 2011. do 2017. gdje su se procjenjivale sledeće situacione motoričke sposobnosti: baratanje loptom (Gardaševic, \& Bjelica, 2014a; Gardašević, Bjelica, Georgiev, \& Popović, 2012), preciznost gađanja loptom (Gardasevic, Popovic, \& Bjelica, 2016), brzina vođenja lopte (Gardasevic i Bjelica, 2014; Gardašević, Bjelica, Popović, \& Milašinović, 2016) i snaga udarca po lopti (Gardasevic, Bjelica, \& Vasiljevic, 2017a; Gardasevic, Bjelica, \& Vasiljevic, 2017b). Takođe je analizirana valjanost upotrijebljenih testova koji su procjenjivali situacione motoričke sposobnosti (Gardašević i Bjelica, 2012) u ovim izdvojenim radovima. Cjelokupan motorički prostor kod fudbalera može se podijeliti prema intenzitetu i kvali- tetu mogućnosti manifestovanja, na bazični i specifični. Bazične motoričke sposobnosti su sposobnosti koje posjeduju svi ljudi, pa prema tome i fudbaleri, međutim oni ih treningom podižu na veći nivo (Gardašević i Goranović, 2011; Gardašević, Bjelica i Popović, 2015; Gardasevic, 2015; Gardašević i sar., 2015; Gardašević, Bjelica i Vasiljević, 2016a; Gardašević, Bjelica i Vasiljević, 2016b; Gardasevic, Bjelica, Milasinovic i Vasiljevic, 2016), a specifične motoričke sposobnosti kod fudbalera su stvorene i razvijane specifičnim trenažnim sredstvima (Bjelica, Popović i Gardašević, 2016b; Gardašević, Vasiljević i Bojanić, 2015; Gardaševic i Vasiljević, 2016). Na današnjem nivou naučnih saznanja zapaža se da se motoričke sposobnosti pojavljuju na određeni način, u veoma različitim zadacima (Gardasevic i Bjelica, 2014b)

Osnovni cilj ovog istraživanja je bio da se uradi meta analiza originalnih naučnih radova objavljenih u časopisu Sport Mont, koji su utvrđivali nivo kvantitativnih promjena situacionih motoričkih sposobnosti kod fudbalera kadetskog uzrasta, pod uticajem programiranog fudbalskog treninga u pripremnom periodu.

\section{Metode}

Analiza sadržaja je metoda često prisutna u istraživanjima koja kvalitativno i kvantitativno sistematizuje objavljene radove na određenu temu, a u jednostavnijem obliku se koriste zbrajanje i deskripcija pomenutih radova. Jedinica analize sadržaja u ovom preglednom radu su naslovi originalnih naučnih istraživanja objavljenih u časopisu „Sport Mont“, kao i na raznim konferencijama, od kojih je najviše objavljenih na onima koje je or- 
ganizovala Crnogorska sportska akademija, od 2011. do 2017. Izdvojeno je sedam objavljenih radova u ovom periodu. Radovi su klasifikovani po jednostavnom kriterijumu, a to je da se bave efektima trenažnog rada tokom pripremnog perioda na transformaciju situaciono motoričkih sposobnosti kod fudbalera kadetskog uzrasta.

\section{Rezultati}

Iz pregleda svih ovih objavljenih originalnih naučnih radova koji se analiziraju, jasno je da je riječ o longitudinalnim istraživanjima sa ciljem da se utvrde kvantitativne promjene situacionih motoričkih sposobnosti kod fudbalera kadetskog uzrasta pod uticajem programiranog trenažnog rada. Riječ je o sledećim radovima: "Transformacija situacionih motoričkih sposobnosti kod fudbalera kadetskog uzrasta" (Gardašević, Bjelica,
Georgiev, \& Popović, 2012), "Efekti treninga u pripremnom periodu na baratanje loptom kod petnaestogodišnjih fudbalera" (Gardaševic, \& Bjelica, 2014a), "Preciznost gađanja loptom nakon pripremnog perioda kod fudbalera U15" (Gardasevic, Popovic, \& Bjelica, 2016), "Efekti rada u pripremnom periodu na brzinu vođenja lopte petnaestogodišnjih fudbalera" (Gardasevic i Bjelica, 2014b), "Pripremni period i njegovi efekti na brzinu vođenja lopte kod fudbalera U16" (Gardašević, Bjelica, Popović, \& Milašinović, 2016), "Snaga udarca po lopti nakon pripremnog perioda kod petnaestogodišnjih fudbalera" (Gardasevic, Bjelica, \& Vasiljevic, 2017a), "Snaga udarca po lopti nakon pripremnog perioda kod fudbalera U15" (Gardasevic, Bjelica, \& Vasiljevic, 2017b), "Valjanost situacijsko-motoričkih testova kod fudbalera kadeta u dobi od 15 godina (U15)" (Gardašević i Bjelica, 2012). Prikazan je i tabelaran pregled objavljenih radova (Tabela 1.)

Tabela 1. Studije koje su analizirale uticaj pripremnog perioda na transformaciju bazičnih motoričkih sposobnosti kod fudbalera kadetskog uzrasta

\begin{tabular}{|c|c|c|c|c|}
\hline Autor & $\begin{array}{c}\text { Cilj } \\
\text { istraživanja }\end{array}$ & $\begin{array}{l}\text { Uzorak/ } \\
\text { varijable }\end{array}$ & $\begin{array}{l}\text { Statist. } \\
\text { analiza }\end{array}$ & Rezultati \\
\hline $\begin{array}{l}\text { Gardašević, } \\
\text { Bjelica, } \\
\text { Georgiev, \& } \\
\text { Popović, (2012) }\end{array}$ & $\begin{array}{l}\text { Efekti pripremnog } \\
\text { perioda na situacione } \\
\text { motoričke sposobnosti }\end{array}$ & $\begin{array}{l}120 \text { fudbalera kadetskog } \\
\text { uzrasta/brzina vođenja, } \\
\text { preciznost, snaga udarca po lopti, } \\
\text { baratanje loptom }\end{array}$ & T-test & $\begin{array}{l}\text { utvrđene su statistički značajne razlike } \\
\text { u svim parovima varijabli između } \\
\text { inicijalnog i finalnog stanja, na nivou } \\
\mathrm{p}<.01\end{array}$ \\
\hline $\begin{array}{l}\text { Gardaševic i } \\
\text { Bjelica, (2014) }\end{array}$ & $\begin{array}{l}\text { Efekti pripremnog } \\
\text { perioda na baratanje } \\
\text { loptom }\end{array}$ & $\begin{array}{l}120 \text { fudbalera kadetskog } \\
\text { uzrasta/udaranje loptom o zid, } \\
\text { vođenje u slalomu, žongliranje }\end{array}$ & T-test & $\begin{array}{l}\text { utvrđene su statistički značajne razlike } \\
\text { u svim parovima varijabli između } \\
\text { inicijalnog i finalnog stanja, na nivou } \\
\mathrm{p}<.01\end{array}$ \\
\hline $\begin{array}{l}\text { Gardasevic, } \\
\text { Popovic, \& } \\
\text { Bjelica, }(2016)\end{array}$ & $\begin{array}{l}\text { Efekti pripremnog } \\
\text { perioda na preciznost } \\
\text { gađanja loptom }\end{array}$ & $\begin{array}{l}120 \text { fudbalera kadetskog uzrasta/ } \\
\text { preciznost nogom i glavom }\end{array}$ & T-test & $\begin{array}{l}\text { utvrđene su statistički značajne razlike } \\
\text { u svim parovima varijabli između } \\
\text { inicijalnog i finalnog stanja, na nivou } \\
\mathrm{p}<.01\end{array}$ \\
\hline $\begin{array}{l}\text { Gardasevic i } \\
\text { Bjelica, (2014) }\end{array}$ & $\begin{array}{l}\text { Efekti pripremnog } \\
\text { perioda na brzinu } \\
\text { vođenja lopte }\end{array}$ & $\begin{array}{l}120 \text { fudbalera kadetskog uzrasta/ } \\
\text { vođenje lopte na } 20 \mathrm{~m} \text {, na } 60 \mathrm{~m}, \mathrm{i} \\
\text { sa promjenom pravca }\end{array}$ & T-test & $\begin{array}{l}\text { utvrđene su statistički značajne razlike } \\
\text { u svim parovima varijabli između } \\
\text { inicijalnog i finalnog stanja, na nivou } \\
\mathrm{p}<.01 \text {. }\end{array}$ \\
\hline $\begin{array}{l}\text { Gardašević, } \\
\text { Bjelica, } \\
\text { Popović, \& } \\
\text { Milašinović, } \\
(2016)\end{array}$ & $\begin{array}{l}\text { Efekti pripremnog } \\
\text { perioda na brzinu } \\
\text { vođenja lopte }\end{array}$ & $\begin{array}{l}120 \text { fudbalera kadetskog uzrasta/ } \\
\text { vođenje lopte na } 20 \mathrm{~m} \text {, na } 60 \mathrm{~m}, \mathrm{i} \\
\text { sa promjenom pravca }\end{array}$ & T-test & $\begin{array}{l}\text { utvrđene su statistički značajne razlike } \\
\text { u svim parovima varijabli između } \\
\text { inicijalnog i finalnog stanja, na nivou } \\
\mathrm{p}<.01\end{array}$ \\
\hline $\begin{array}{l}\text { Gardasevic, } \\
\text { Bjelica, \& } \\
\text { Vasiljevic, } \\
(2017 \mathrm{a})\end{array}$ & $\begin{array}{l}\text { Efekti pripremnog } \\
\text { perioda na snagu } \\
\text { udarca po lopti }\end{array}$ & $\begin{array}{l}120 \text { fudbalera kadetskog uzrasta/ } \\
\text { nogom sa loptom na zemlji, } \\
\text { nogom sa loptom u vazduhu i } \\
\text { glavom }\end{array}$ & T-test & $\begin{array}{l}\text { utvrđene su statistički značajne razlike } \\
\text { u svim parovima varijabli između } \\
\text { inicijalnog i finalnog stanja, na nivou } \\
\mathrm{p}<.01\end{array}$ \\
\hline $\begin{array}{l}\text { Gardasevic, } \\
\text { Bjelica, \& } \\
\text { Vasiljevic, } \\
(2017 \mathrm{~b})\end{array}$ & $\begin{array}{l}\text { Efekti pripremnog } \\
\text { perioda na snagu } \\
\text { udarca po lopti }\end{array}$ & $\begin{array}{l}120 \text { fudbalera kadetskog uzrasta/ } \\
\text { nogom sa loptom na zemlji, } \\
\text { nogom sa loptom u vazduhu i } \\
\text { glavom }\end{array}$ & T-test & $\begin{array}{l}\text { utvrđene su statistički značajne razlike } \\
\text { u svim parovima varijabli između } \\
\text { inicijalnog i finalnog stanja, na nivou } \\
\mathrm{p}<.01\end{array}$ \\
\hline
\end{tabular}

\section{Diskusija}

U ovom radu su izdvojena originalna istraživanja objavljena u časopisu "Sport Mont", kao i na konferencijama, od kojih je najviše objavljenih na onima koje je organizovala Crnogorska sportska akademija, od 2011. do 2017. Radovi iz sportskih nauka objavljenih u "Sport Montu", u koje spadaju i svi ovi izdvojeni, su najcitiraniji i najbolje kotirani, pa je to i razlog napredovanja časopisa u smjeru najviših naučnih baza u sportskim naukama. Utvrđeno je da su objavljeni radovi imali za teme jednu od najsavremenijih tendencija u sportskim naukama, ispitivanje uticaja trenažnog rada u pripremnom periodu na transformaciju situaciono motoričkih sposobnosti kod kadetskog uzrasta fudbalera, koji je ujedno i najkritičniji uzrast u čitavom njihovom razvoju. Ta istraživanja mogu biti korisna i za dalja teorijska istraživanja, kao i za sportske praktičare.

$\mathrm{Na}$ osnovu uvida u dobijene parametre u navedenim objavljenim originalnim naučnim radovima, može se zaključiti da su statistički značajni parcijalni kvantitativni efekti (promjene) kod svih varijabli za procjenu situaciono motoričkih sposobnosti dobijeni kao rezultat primijenjenog trenažnog programa u pripremnom periodu. Statistički značajna poboljšanja koja su se dogodila kod ovih varijabli posledica su detaljno i studiozno pripremljenog trenažnog programa rada koji obiluje raznovrsnim vježbama. Može se zaključiti da je trenažni program rada u pripremnom periodu doveo do pozitivnih transformacija kod 
svih varijabli koje su procjenjivale (po strukturi hipotetski postavljenog modela) situacione motoričke sposobnosti. U svim ovim objavljenim originalnim naučnim radovima, vidi se da su se autori rukovodili činjenicom da je ovakav trenažni program rada u pripremnom periodu, veoma efikasan u pogledu podizanja nivoa motoričkih sposobnosti fudbalera kadetskog uzrasta (Gardaševic, \& Bjelica, 2014; Gardašević i Bjelica, 2013; Bjeli-

\section{R E F E R E N C E S}

Bjelica, D., Gardasević, J., Georgiev, G., Popović, S., \& Petković, J. (2012). Validity of the Applied Motor Tests for Estimating Basic Motor Abilities of Football Players-U15. Research in physical education, sport and health, 1(2), 21-25.

Bjelica, D., i Popović, S. (2012). Fudbal-teorija, tehnika i taktika. Podgorica: Crnogorska sportska akademija.

Bjelica, D., Popović, S., i Gardašević, J. (2016a). Modeli fizičke pripreme vrhunskih sportaša i doziranje opterećenja. Zbornik radova 14.godišnje međunarodne konferencije "Kondicijska priprema sportaša" (185-189), Zagreb: Udruga kondicijskih trenera Hrvatske.

Bjelica, D., Popović, S., i Gardašević, J. (2016b). Opći principi planiranja i programiranja fizičkih priprema sportaša. Zbornik radova 14.godišnje međunarodne konferencije "Kondicijska priprema sportaša” (190-192), Zagreb: Udruga kondicijskih trenera Hrvatske.

Corluka, M., \& Vasiljevic, I. (2018). Differences in the morphological characteristics and body composition of football players in Montenegro. Journal of Anthropology of Sport and Physical Education, 2(1), 3-7. doi: 10.26773/jaspe.180101

Gardašević, J. (2010). Efekti programiranog rada u pripremnom periodu na transformaciju bazično-motoričkih $i$ situaciono-motoričkih sposobnosti kod fudbalera kadetskog uzrasta. Neobjavljena magistarska teza. Nikšić: Fakultet za sport i fizičko vaspitanje.

Gardašević, J., i Goranović, K. (2011). Efekti programiranog rada u pripremnom periodu na transformaciju eksplozivne snage kod fudbalera kadeta. Sport Mont, 9(28-29-30), 55-62.

Gardašević, J., Georgiev, G., \& Bjelica, D. (2012). Qualitative changes of basic motor abilities after completing a six-week training programme. Acta Kinesiologica, 6(1), 70-74.

Gardašević, J., Bjelica, D., Georgiev, G., \& Popović, S. (2012). Transformation of situational motor abilities with football players-cadets. Proceeding book, XVI International Scientific Congress "Olympic Sports and Sport for All" \& VI International Scientific Congress „,Sport, Stress, Adaptation” (373377), Sofia: National Sports Academy "Vassil Levski".

Gardašević, J., i Bjelica, D. (2012). Valjanost situacijsko-motoričkih testova kod fudbalera kadeta u dobi od 15 godina (U15). Sport Mont, 10(34-35-36), 488-493.

Gardašević, J., i Bjelica, D. (2013). Efekti programiranog trenažnog rada u trajanju od šest nedjelja na transformaciju fleksibilnosti kod fudbalera kadetskog uzrasta. Sport Mont, 11(37-38-39), 212-217.

Gardaševic, J., \& Bjelica, D. (2014a). The effects of the training in the preparation period on the dribbling speed with fifteen years old football players. Book of Abstracts of the 11th International Scientific Conference on Transformation Process in Sport "Sport Performance" (22-23), Podgorica: Montenegrin Sports Academy.

Gardasevic, J., i Bjelica, D. (2014b). Efekti rada u pripremnom periodu na brzinu vođenja lopte petnaestogodišnjih fudbalera. Sport Mont, 12(40-41-42), 160-166. ca, Gardasević, Georgiev, Popović, \& Petković, 2012). Autori su zaključili da je pripremni period sa ovakvim trenažnim programom rada, optimalan za podizanje situacionih motoričkih sposobnosti na nivo potreban za takmičenje u kadetskom uzrastu fudbalera. Dobijeni rezultati se mogu usmjeriti u pravcu inoviranja planova i programa rada u pripremnom periodu, te prilagođavanju istih potrebama dotične populacije.

Gardašević, J., Vasiljević, I., \& Bojanić, D. (2015). Six-week preparation period and its effects on coordination transformation with football players under 16. Book of Abstracts 11th International Scientific Conference Management, Sport, Olympism (36), Beograd: Fakultet za menadžment u sportu, Alfa univerzitet.

Gardasevic, J. (2015). The effects of the training in the preparation period on the agility transformation with cadet level football players. Book of Abstracts of the 12th International Scientific Conference on Transformation Process in Sport "Sport Performance" (76-77), Podgorica: Montenegrin Sports Academy.

Gardašević, J., Vasiljević, I., Bojanić, D., Muratović, A., Ljubojević, M., Milašinović, R., \& Bubanja, M. (2015). Sixweek Preparation Period and its Effects on Transformation Movement Speed with Football Players Under 16. Book of Abstracts, International Scientific Conference "Effects of Physical Activity Application to Anthropological Status with Children, Youth and Adults " (148), Belgrade:University of Belgrade: Faculty of Sport and Physical Education.

Gardašević, J., Bjelica, D., i Popović S. (2015). Efekti programiranog rada tokom pripremnog perioda na transformaciju agilnosti kod fudbalera kadetskog uzrasta. Sport Mont, 13(43-44-45), 355-360.

Gardašević, J., Bjelica, D., \& Vasiljević, I. (2016a). Six-Week Preparation Period and its Effects on Transformation Movement Speed with Football Players Under 16. Sport Mont, 14(1), 13-16.

Gardašević, J., Bjelica, D., \& Vasiljević, I. (2016b). The Effects of the Training in the Preparation Period on the Repetitive Strength Transformation With Cadet Level Football Players. Book of Abstracts of the 13th International Scientific Conference on Transformation Processes in Sport "Sport Performance" (43), Podgorica: Montenegrin Sports Academy.

Gardasevic, J., Bjelica, D., Milasinovic, R., \& Vasiljevic, I. (2016). The Effects of the Training in the Preparation Period on the Repetitive Strength Transformation with Cadet Level Football Players. Sport Mont, 14(2), 31-33.

Gardaševic, J., \& Vasiljević, I. (2016). Effects of Preparation Period on Endurance in U16 Football Players. Book of Abstracts of the $4^{\mathrm{TH}}$ International Scientific Conference "Exercise and Quality of Life" (108), Novi Sad: University of Novi Sad, Faculty of Sport and Physical Education.

Gardašević, J., Bjelica, D., Popović, S., \& Milašinović, R. (2016). Preparation Period and its Effects on the Speed of Ball Leading at Players U16. In Book of Summaries of 11th FIEP European Congress "Anthropological Aspects of Sport, Physical Education and Recreation" (30-31), Banjaluka: University of Banjaluka, Faculty of Physical Education and Sport.

Gardasevic, J., Popovic, S., \& Bjelica, D. (2016). After preparation period ball shooting accuracy at players U15. In $A b$ stract Book of the 8th Conference for Youth Sport (88), Ljubljana: University of Ljubljana, Faculty of Sport. 
Gardasevic, J., Bjelica, D., \& Vasiljevic, I. (2017a). The strength of kicking the ball after preparation period with U15 football players. Book of Abstracts of the 14th International Scientific Conference on Transformation Processes in Sport "Sport Performance" (65-66), Podgorica: Montenegrin Sports Academy.

Gardasevic, J., Bjelica, D., \& Vasiljevic, I. (2017b). The Strength of Kicking the Ball after Preparation Period with U15 Football Players. Sport Mont, 15(2), 39-42.

Gardasevic, J., Bjelica, D., Popovic, S., Vasiljevic, I., \& Milosevic, Z. (2018). Differences in the morphological characteristics and body composition of football players FC Buducnost and FC Mladost in Montenegro. Journal of Anthropology of Sport and Physical Education, 2(1), 51-55. doi: 10.26773/jaspe. 180109
Sermaxhaj, S., Popovic, S., Bjelica, D., Gardasevic, J., \& Arifi, F. (2017). Effect of recuperation with static stretching in isokinetic force of young football players. Journal of Physical Education and Sport, 17(3), 1948-1953. doi: 10.7752/jpes.2017.03191

Vasiljević, I., Gardašević, J., i Bojanić, D. (2013). Uporedna analiza motoričkog prostora između aktivnih fudbalera kadetskog uzrasta i učenika srednje škole. Zbornik naučnih $i$ stručnih radova VI međunarodni simpozijum "Sport i zdravlje” (212-215), Tuzla: Fakultet za tjelesni odgoj i sport.

Vasiljevic, I. (2017). Meta-analyze of the scientific papers on the effects of the preparation period on the basic motor skills of the cadet football players. Journal of Anthropology of Sport and Physical Education, 1(1), 29-32. doi: 10.26773/jaspe. 171005

\section{Vasiljevic}

University of Montenegro, Faculty for Sport and Physical Education, Narodne omladine bb, Niksic, Montenegro e-mail:vasiljevic.ivan301@gmail.com 